\title{
Gender Symmetry in the Self-Reporting of Intimate Partner Violence
}

Journal of Interpersonal Violence $\mathrm{XX}(\mathrm{X}) \mathrm{I}-24$

(C) The Author(s) 2011 Reprints and permission: http://www. sagepub.com/journalsPermissions.nav DOI: $10.1|77 / 08862605|$ |416463 http://jiv.sagepub.com

@SAGE

\section{Ko Ling Chan' [AQ: 1]}

\begin{abstract}
Research has not conclusively determined whether men and women are equally likely to commit intimate partner violence (IPV). One explanation for the disparity in previous findings may be gender-based differences in reporting styles. The present study investigated whether there was any gender difference in self-reported IPV prevalence. A total of 3,740 Chinese couples from a representative population in Hong Kong were interviewed. Self-reports of men-to-women and women-to-men IPV between spouses were compared. Gender was controlled for to evaluate whether age, education, the Chinese concept of face, and other violence-related characteristics would affect the self-reporting of IPV. Findings supported gender symmetry in self-reported IPV prevalence as well as a moderate interspousal agreement in the self-reports. After adjustment for covariates, face was a significant factor predicting the interspousal differences in both men-to-women and women-to-men physical IPV.
\end{abstract}

\section{Keywords}

reporting, gender symmetry, intimate partner violence, Chinese

\footnotetext{
'University of Hong Kong, Hong Kong, China
}

\section{Corresponding Author:}

Ko Ling Chan, Department of Social Work and Social Administration, The University of Hong Kong, Pokfulam, Hong Kong 852, SAR, China.

Email: eklchan@hkucc.hku.hk 
The question of whether there is a gender symmetry or difference in the prevalence, frequency, and severity of perpetration of violence against intimate partners remains controversial. Some researchers have found evidence for a gender difference in the perpetration of intimate partner violence (IPV) involving male perpetrators and female victims (Rennison \& Welchans, 2000; Tjadens \& Thoennes, 1998). Major empirical findings include that IPV is primarily committed by men (Tjadens \& Thoennes, 2000) and that women are more likely to be injured (Rennison \& Welchans, 2000) and to report more severe and more frequent IPV in a mutually violent relationship (Weston, Temple, \& Marshall, 2005). Other researchers have suggested gender symmetry in IPV perpetration based on their findings that women are as violent as men and most IPV acts are mutual and bidirectional (i.e., both partners are violent; Straus, 2005, 2008, 2009; Straus, Gelles, \& Steinmetz, 2006; Straus \& Ramirez, 2007). Reviews of IPV and findings from meta-analyses also point to gender symmetry in IPV perpetration (Archer, 2000; Fiebert, 1997; Straus, 2010). In regard to the mixed findings on IPV prevalence rates, the present study explores possible explanations for the discrepancy of research findings.

\section{Gender Symmetry or Asymmetry in IPV}

Archer (2000) noted that there were two "clearly stated hypotheses" that may explain the discrepancy in gender symmetry or asymmetry in the prevalence of IPV (p. 651). The first hypothesis focuses on the inability of existing measures (in particular, the Conflict Tactics Scales or CTS) to capture the context, motives, causes, and consequences of IPV (Dutton, 1994), which often results in the finding of a gender symmetry in IPV prevalence. Archer's second hypothesis concerns the disparity in the samples used in different studies. Johnson (1995) pointed out that studies using representative samples of married, cohabiting, and dating couples yielded very different results than those using women from refuges or men in violence treatment programs. For example, the ratio of IPV perpetration was 1 (men):1 (women) using the former, and 17 (men):1 (women) using the latter. Straus (1997) also noted that most IPV cases revealed in surveys were minor, infrequent, and mutual, whereas most officially reported cases involved severe violence against women that required medical attention.

In a recent article, Straus (2010) has also suggested several possible reasons, which nevertheless can be highly controversial, contributing to the controversy over gender symmetry or asymmetry in the past few decades. Straus believed that men and women are equally likely in perpetrating IPV, and the 
discrepancy in research findings are mainly due to the denial, concealment, and distortion of results supporting gender symmetry in past studies. Examples of the methods to conceal and distort those results include "avoid obtaining evidence on female perpetration" (p. 340), "selective citation of research" (p. 341), and "block publication of articles that report gender symmetry" (p. 343). Despite the difficulties in proving Straus' claim, biased coverage of research findings can be one reason causing the presence of mixed results in IPV literature.

Gender differences in IPV reporting or disclosure-which may stem from the reliance on self-reports in IPV studies - may offer another explanation for the discrepancy in research findings. Men and women may exhibit different patterns of reporting, which can, in turn, affect conclusions about the prevalence of IPV (Dobash \& Dobash, 2004). Gender may be one factor that significantly influences disclosure and reporting of IPV, and researchers generally agree that some IPV cases involve gender-biased reporting (Caetano, Field, Ramisetty-Mikler, \& Lipsky, 2009; Caetano, Schafer, Field, \& Nelson, 2002). Factors found to shape the gender-specific (under)reporting pattern of IPV include social desirability (Rosenbaum \& Langhinrichsen-Rohling, 2006), shame, and guilt (Knapp \& Kirk, 2003). Respondents who bear a high level of social desirability have a stronger desire to be viewed positively and are more likely to underreport IPV incidents, which are socially undesirable. Indeed, Arias and Beach (1987[AQ: 2]) reported a negative association between social desirability and the willingness to report physical violence perpetration. Underreporting may occur even more frequently during in-person interviews, in which the face-to-face disclosure of socially undesirable IPV behavior may evoke feelings of shame, guilt, and embarrassment (Felson \& Paré, 2005; Knapp \& Kirk, 2003).

Culture-specific factors may interact with gender to affect the reporting styles of IPV. For example, the concept of "face" has tremendous influence on the disclosure of social undesirable behaviors within the Chinese culture. Face can be viewed as "prestige; dignity; honor; respect; status" (Carr, 1993, p. 90) that can be gained or lost through social interactions. "Losing face" is extremely undesirable in the Chinese culture; the avoidance of face-losing situations has shaped the behaviors of Chinese people (Eberhard, 1967), especially when immoral acts are involved. The influence of "face" is especially great among Chinese men, who have been found to have a higher tendency to feel greater pressure to present themselves as capable, as well as to avoid "losing face" (Li, 1999). IPV is a socially unacceptable behavior; disclosure of one's experience of it to others, for example, other family members, friends, or even health professionals and survey interviewers, would 
probably evoke shame and embarrassment and induce a sense of "losing face" (Felson \& Paré, 2005). To prevent placing themselves in such undesirable situations, Chinese people who highly value "face" may refrain from disclosing IPV (Chan, 2009).

\section{Agreement Studies of IPV Reporting}

Considering that gender-specific reporting styles may mask the actual prevalence of IPV across gender, there is a growing body of research that examines the agreement between men's and women's self-reports of IPV. According to Armstrong et al., there are two ways to obtain prevalence rates using couple data: (a) lower bound estimates, which only count IPV occurrence when both partners have reported violence, and (b) upper bound estimates, which count occurrence when either partner has reported IPV incidence. Overall, the agreement between self-reported IPV prevalence across gender is low to moderate (Armstrong, Wernke, Medina, \& Schafer, 2002). For example, Szinovacz (1983) showed that the rate of IPV based on upper bound estimate was 50\% higher than the rate based on husbands' reports only and 20\% higher than that based on wives' reports only. Szinovacz and Egley (1995) found that the IPV rates as counted with female-data or male-data differed considerably from those using lower bound estimates, and people tended to underreport both violence perpetration and victimization. Using community sample of 360 couples, Moffitt et al. (1997) found poor-to-fair levels of interspousal agreement, with a mean kappa value of .36 . However, a more recent study by Heckert and Gondolf (2000) used a clinical sample of 588 couples of which the men were receiving intervention programs for battering and revealed a range of levels of agreement between $17 \%$ and $74 \%$. In regard to the possibility of underreporting by both men and women, using one-partner data may confound the results. Therefore, it has been suggested that, when possible, couple data should be used to form a more accurate and complete set of empirical data (Straus, 2006).

\section{The Present Study}

Existing studies of agreement between men's and women's self-reports of IPV originate mainly from Western societies. Chinese culture emphasizes family honor and face-saving. These factors might influence the self-reporting of partner violence (Chan, 2009) as Chinese society tends to stress the importance of keeping family matters private to minimize conflicts that might bring shame to the family (Ho, 1990[AQ: 3]). The impact of Chinese culture on 
the self-reporting of IPV may thus lead to key differences from previous Western studies. Using a large, representative matched sample of Chinese couples in Hong Kong, the present study investigated the reporting of IPV across gender. In particular, it examined (a) whether there is any difference in the self-reporting of IPV across gender and/or between perpetrators and victims and (b) whether there are any other factors affecting the self-reporting of IPV (e.g., age, education, and social desirability) when gender is controlled for. On the basis of existing literature on agreement of self-reports between spouses, the present study expected a moderate level of interspousal agreement in the self-reported prevalence rates of IPV.

\section{Method}

\section{Sample}

Data were obtained from a representative household survey study conducted in Hong Kong in 2004. In this study, eligible households were selected using stratified random sampling. Chinese couples living in the sampled households were invited to participate if they met the following criteria: aged 16 or above; Cantonese, Mandarin, or English speaking; married or cohabitating; and able to give informed consent during the study period. Of the eligible participants, a total of 5,049 respondents agreed to participate and were successfully interviewed, representing a response rate of $70 \%$. Face-to-face interviews were conducted individually with all participants by trained interviewers. For items on sensitive topics, respondents were provided with a separated, self-administered questionnaire which was to be completed and sealed in an envelope by the respondents themselves. This was to ensure respondents' privacy and to avoid their partners knowing their disclosure of any IPV. On completion of the interview, respondents were also given a card containing information about social services related to violence prevention. All procedures were approved by the Ethics Committee of The University of Hong Kong. For more detailed information on recruiting and surveying procedures, see Chan (2005).

The present study employed a subsample of data from a 2004 survey study. Self-report records of 1,870 pairs of couples (1,870 men and 1,870 of their female partners; $N=3,740$ ) were included in the analysis. Among the participating couples, $98 \%$ were married and about $14 \%$ had an interspousal age difference of more than 10 years $(M=4.5 ; S D=4.5)$. The complete demographic profile is shown in Table 1. 
Table I. Demographic Profile of the Couples

\begin{tabular}{|c|c|c|c|}
\hline & $\begin{array}{c}\text { Female } \\
(n=I, 870)\end{array}$ & & $\begin{array}{c}\text { Male } \\
(n=1,870)\end{array}$ \\
\hline Characteristics & $\%$ & & $\%$ \\
\hline \multicolumn{4}{|l|}{ Age } \\
\hline Under 34 & 16.5 & & 9.0 \\
\hline $35-54$ & 61.3 & & 59.5 \\
\hline 55 or above & 22.2 & & 31.5 \\
\hline \multicolumn{4}{|l|}{ Education $^{\mathrm{a}}$} \\
\hline F3 or below & 61.1 & & 58.7 \\
\hline F4-F7 & 30.2 & & 28.9 \\
\hline Tertiary or above & 8.7 & & 12.4 \\
\hline Spouse age difference ( 10 years or above) & & 13.8 & \\
\hline \multicolumn{4}{|l|}{ Marital status } \\
\hline Married & & 98.1 & \\
\hline Cohabiting & & 1.9 & \\
\hline
\end{tabular}

a. F3 or below = Grade 9 or below in the United States; F4-F7 = Grade 10 to Grade 12 (or high school) in the United States; Tertiary or above = university, college, vocational education, or above.

\section{Measures}

IPV. The validated Chinese version of the Revised Conflict Tactics Scale (CTS2) was used to capture the prevalence of both lifetime IPV and IPV of the preceding year (Chan, 2004). The CTS2 covers five aspects of spousal conflict: negotiation, physical assault, psychological aggression, physical injury, and sexual violence. It has satisfactory psychometric characteristics (Straus, Hamby, Boney-McCoy, \& Sugarman, 1996), high cross-cultural reliability (Straus, 2004), and satisfactory criterion validity (Coben, Forjuoh, \& Gondolf, 1999). The internal consistencies of the CTS2 subscales have been found to be satisfactory, with Cronbach's alpha ranging from .79 to .95 in the initial study (Straus et al., 1996) and from .88 to .96 in the present study.

The subscales of Physical Assault, Psychological Aggression, Sexual Violence, and Injury were selected in the present study. The CTS2 subscales can be divided into minor and severe levels. Items used to score severe level of IPV are generally considered to pose a greater risk of injury which would require medical attention than those used to score minor level. Sample severe items include "used a knife or gun on my partner" and "had a broken bone from 
a fight with my partner." For minor items, examples include "shouted or yelled at my partner" and "grabbed my partner."

Participants were asked to report their perpetration of violence to their current partner (i.e., the one who did the interview together with them during the 2004 survey study), as well as their victimization of violence from the partner, using a "yes" or "no" version of CTS2 items. This resulted in a profile of both men-to-women IPV and women-to-men IPV from each spouse. For example, women's report of perpetration of physical assault against their current partner would be coded as having experienced women-to-men physical assault, whereas their report of victimization of psychological aggression would be coded as having experienced men-to-women psychological aggression.

Participants were also asked if any of the four types of violence had occurred during the year preceding the interview. Using the same coding approach, the men-to-women and women-to-men physical assault, psychological aggression, sexual violence, and injury that occurred in the preceding year, as reported by each partner, were also computed for analysis.

Violence-related factors. The Personal and Relationship Profile (PRP) is a 21-factor self-report scale measuring the individual and relationship factors that are theoretically related to the etiology of IPV (Straus et al., 1999). Three factors (subscales) were selected-negative attribution, violence approval, and social desirability - and were translated into Chinese using the back-translation procedure. These three subscales were selected from the PRP because they focus on one's attitude toward violence which may affect reporting or disclosure of family violence (Ashton, 2004; Rosenbaum \& Langhinrichsen-Rohling, 2006). Items were rated on a 4 -point scale $(1=$ strongly disagree, $4=$ strongly agree) and the item scores in each subscale were summed to give a subscale score. The definitions and internal consistencies of the selected PRP subscales are shown in Table 2.

Face. The Acquisitive Face Orientation Scale (AFOS) was used to measure the potential of an individual to highly value prestige, success, and others' respect. The AFOS is a validated 10 -item scale rated on a 4-point scale $(1=$ strongly disagree, $4=$ strongly agree ). A higher score indicates a higher level of face orientation, showing a stronger feeling of "losing face" when one fails to achieve prestige. The internal consistencies have been found to be satisfactory to good, with Cronbach's alpha ranging from .70 in a previous study (Wang, 2002) to .88 in the present study.

Demographic characteristics. Respondents were asked about their age, education level, and marital status. An interspousal age difference was also calculated for each matched couple. 
Table 2. Definitions and Reliability Coefficients of the Selected Subscales of the Personal and Relationship Profile (PRP)

\begin{tabular}{|c|c|c|c|}
\hline PRP Subscales & $N$ of items & Alpha & Brief Description \\
\hline $\begin{array}{l}\text { Negative } \\
\text { attribution }\end{array}$ & 4 & .73 & $\begin{array}{l}\text { Blame/negative intentions attributed to } \\
\text { partner of respondent }\end{array}$ \\
\hline $\begin{array}{l}\text { Violence } \\
\text { approval }\end{array}$ & 9 & .73 & $\begin{array}{l}\text { The extent to which use of physical } \\
\text { force is acceptable in a variety of } \\
\text { interpersonal situations }\end{array}$ \\
\hline $\begin{array}{l}\text { Social } \\
\text { desirability }\end{array}$ & 13 & .61 & $\begin{array}{l}\text { The degree to which a respondent will } \\
\text { tend to avoid admitting undesirable } \\
\text { behavior, such as partner assault and } \\
\text { other forms of crime }\end{array}$ \\
\hline
\end{tabular}

\section{Statistical Analyses}

Comparison of rates of IPV. Using chi-square tests, we compared the selfreporting rates of IPV perpetration and victimization across gender by type (physical, psychological, sexual, and injury) and by severity (minor and severe).

Agreement of IPV reporting across gender. The use of a matched-couple sample in the present study allowed for a comparison of IPV reporting between spouses and facilitated the computation of agreement between male and female reporting. To compare the self-reports of men-to-women and womento-men IPV between spouses, Cohen's kappa coefficient analysis was employed both for categorical and continuous data.

Factors affecting the disagreement in male and female reports. Disagreement was defined as any discrepancy in the responses to CTS2 items between spouses. Logistic regression analyses were conducted to study the effect of age group (which was categorized as "below 34," "35-54," and "55 or above" [the reference group]), education level (which was categorized as "Secondary 3/Grade 9 or below," "Secondary 4 to 7/Grade 10 to 12," and "Tertiary or above/university, college, vocational education, or above" [the reference group]), face, and the selected PRP factors (negative attribution, violence approval, and social desirability) on the disagreement in spouses' reports.

\section{Results}

\section{Gender Differences in Reported Rates of IPV}

The prevalence of IPV perpetration as reported by the respondents is shown in Table 3. There was no significant gender difference in the prevalence of 
Table 3. Self-Reported Prevalence of IPV Perpetration Across Gender

\begin{tabular}{|c|c|c|c|c|}
\hline IPV & $\frac{\begin{array}{c}\text { Total } \\
(N=3,740)\end{array}}{\%}$ & $\begin{array}{c}\begin{array}{c}\text { Male } \\
(n=1,870)\end{array} \\
\%\end{array}$ & $\begin{array}{c}\begin{array}{c}\text { Female } \\
(n=1,870)\end{array} \\
\%\end{array}$ & $\chi^{2}$ \\
\hline \multicolumn{5}{|l|}{ Lifetime } \\
\hline \multicolumn{5}{|l|}{ Physical } \\
\hline Overall & 9.9 & 9.4 & 10.5 & 1.136 \\
\hline Severe & 3.4 & 3.4 & 3.5 & 0.064 \\
\hline Minor & 9.6 & 9.2 & 10.1 & 0.836 \\
\hline \multicolumn{5}{|c|}{ Psychological } \\
\hline Overall & 54.2 & 53.9 & 54.4 & 0.076 \\
\hline Severe & 19.0 & 18.3 & 19.7 & 1.134 \\
\hline Minor & 53.2 & 53.1 & 53.4 & 0.044 \\
\hline \multicolumn{5}{|l|}{ Sexual } \\
\hline Overall & 6.9 & 7.8 & 5.9 & $4.925 *$ \\
\hline Severe & 1.6 & 1.8 & 1.3 & 1.443 \\
\hline Minor & 6.8 & 7.7 & 5.9 & $4.395 *$ \\
\hline \multicolumn{5}{|l|}{ Injury } \\
\hline Overall & 3.3 & 3.3 & 3.3 & 0.003 \\
\hline Severe & 1.5 & 1.5 & 1.5 & 0.001 \\
\hline Minor & 3.2 & 3.2 & 3.2 & 0.003 \\
\hline \multicolumn{5}{|c|}{ Preceding year } \\
\hline \multicolumn{5}{|c|}{ Physical } \\
\hline Overall & 5.8 & 5.5 & 6.0 & 0.566 \\
\hline Severe & 1.4 & 1.4 & 1.5 & 0.016 \\
\hline Minor & 5.5 & 5.3 & 5.7 & 0.305 \\
\hline \multicolumn{5}{|c|}{ Psychological } \\
\hline Overall & 48.3 & 47.5 & 49.2 & 1.007 \\
\hline Severe & 35.9 & 34.3 & 37.6 & $4.489 *$ \\
\hline Minor & 39.5 & 38.7 & 40.3 & 0.936 \\
\hline \multicolumn{5}{|l|}{ Sexual } \\
\hline Overall & 3.6 & 4.0 & 3.2 & 1.540 \\
\hline Severe & 0.4 & 0.5 & 0.2 & 1.930 \\
\hline Minor & 3.5 & 3.9 & 3.2 & 1.148 \\
\hline \multicolumn{5}{|l|}{ Injury } \\
\hline Overall & 1.6 & 1.7 & 1.5 & 0.092 \\
\hline Severe & 0.3 & 0.4 & 0.3 & 0.355 \\
\hline Minor & 1.5 & 1.5 & 1.5 & 0.030 \\
\hline
\end{tabular}


IPV perpetration, except for severe psychological aggression, and overall and minor sexual violence. It was found that a greater proportion of male spouses reported lifetime sexual violence perpetration at a minor level $(7.7 \%$ vs. $\left.5.9 \% ; \chi^{2}=4.39, p<.05\right)$. With regard to overall sexual violence, men were more likely to perpetrate lifetime sexual violence $\left(7.8 \%\right.$ vs. $5.9 \% ; \chi^{2}=$ $4.92, p<.05)$. For the IPV perpetration in the preceding year, a significant gender difference was revealed in cases of severe psychological aggression only, and women were more likely to report severe psychological violence perpetration than men $\left(37.6 \%\right.$ vs. $\left.34.3 \% ; \chi^{2}=4.48, p<.05\right)$.

Table 4 compares the prevalence of IPV victimization as reported by male and female spouses. Similar to IPV perpetration, only the rates of overall and minor sexual violence victimization were found to be different across gender. More women than men reported being victims of sexual violence, both overall $\left(8.3 \%\right.$ vs. $\left.4.7 \% ; \chi^{2}=19.7, p<.05\right)$ and at a minor level $\left(8.3 \%\right.$ vs. $4.6 \% ; \chi^{2}=$ $20.4, p<.05)$. A similar pattern was found in the reported IPV victimization from the preceding year. Female spouses were more likely to report being a victim of overall sexual violence $\left(4.6 \%\right.$ vs. $\left.2.4 \% ; \chi^{2}=12.7, p<.05\right)$ and of sexual violence at a minor level $\left(4.6 \%\right.$ vs. $\left.2.3 \% ; \chi^{2}=13.5, p<.05\right)$ over the past year.

\section{Agreement on the Reporting of IPV Across Gender}

Table 5 compares spouses' reports on men-to-women IPV. Among all types of IPV, the reports on lifetime psychological aggression were significantly different across gender. Men were more likely than women to report lifetime men-to-women psychological aggression (Overall: $53.9 \%$ vs. $50.2 \% ; \chi^{2}=$ 5.99, $p<.05$; Minor: $53.1 \%$ vs. $49.0 \% ; \chi^{2}=5.02, p<.05$ ). Matched couple reports showed that the percentages of interspousal agreement ranged from $77.45 \%$ to $99.33 \%$. The kappa coefficients, which indicate the agreement on matched-couple reports, ranged from .370 to .593 , generally representing a moderate agreement on the disclosure of IPV between spouses (Landis \& Koch, 1977). Severe sexual violence and severe injury were found to have smaller kappa values (.113 and .140, respectively), implying that only a slight agreement existed between those reports across gender.

The results of the comparison between male and female reports on womento-men IPV are shown in Table 6. Again, only the reports on psychological aggression showed significant differences, with a greater proportion of women reporting lifetime women-to-men psychological aggression at all levels of violence (Overall: $54.4 \%$ vs. $48.9 \% ; \chi^{2}=11.18, p<.05$; Severe: $19.7 \%$ vs. $17.1 \% ; \chi^{2}=3.97, p<.05$; Minor: $53.4 \%$ vs. $47.8 \% ; \chi^{2}=11.53, p<.05$ ). 
Table 4. Self-Reported Prevalence of IPV Victimization Across Gender

\begin{tabular}{|c|c|c|c|c|}
\hline IPV & $\frac{\begin{array}{c}\text { Total } \\
(N=3,740)\end{array}}{\%}$ & $\begin{array}{c}\begin{array}{c}\text { Male } \\
(n=1,870)\end{array} \\
\%\end{array}$ & $\frac{\begin{array}{c}\text { Female } \\
(n=1,870)\end{array}}{\%}$ & $\chi^{2}$ \\
\hline \multicolumn{5}{|l|}{ Lifetime } \\
\hline \multicolumn{5}{|l|}{ Physical } \\
\hline Overall & 8.7 & 8.8 & 8.7 & 0.010 \\
\hline Severe & 3.2 & 3.0 & 3.4 & 0.617 \\
\hline Minor & 8.5 & 8.6 & 8.5 & 0.002 \\
\hline \multicolumn{5}{|c|}{ Psychological } \\
\hline Overall & 49.6 & 48.9 & 50.2 & 0.696 \\
\hline Severe & I7.1 & I7.1 & 17.0 & 0.004 \\
\hline Minor & 48.4 & 47.8 & 49.0 & 0.556 \\
\hline \multicolumn{5}{|l|}{ Sexual } \\
\hline Overall & 6.5 & 4.7 & 8.3 & $19.764 * * *$ \\
\hline Severe & 1.5 & 1.5 & 1.4 & 0.030 \\
\hline Minor & 6.5 & 4.6 & 8.3 & $20.453^{* * *}$ \\
\hline \multicolumn{5}{|l|}{ Injury } \\
\hline Overall & 3.6 & 3.3 & 3.9 & 1.268 \\
\hline Severe & 1.6 & 1.4 & 1.8 & $\mathrm{I} .054$ \\
\hline Minor & 3.5 & 3.1 & 3.8 & 1.307 \\
\hline \multicolumn{5}{|c|}{ Preceding year } \\
\hline \multicolumn{5}{|c|}{ Physical } \\
\hline Overall & 4.6 & 4.6 & 4.6 & 0.005 \\
\hline Severe & 1.3 & 1.3 & 1.4 & 0.011 \\
\hline Minor & 4.5 & 4.5 & 4.5 & 0.000 \\
\hline \multicolumn{5}{|c|}{ Psychological } \\
\hline Overall & 45.1 & 44.3 & 45.8 & 0.862 \\
\hline Severe & 33.0 & 32.4 & 33.5 & 0.455 \\
\hline Minor & 36.3 & 35.4 & 37.2 & 1.366 \\
\hline \multicolumn{5}{|l|}{ Sexual } \\
\hline Overall & 3.5 & 2.4 & 4.6 & $12.77 \mid * * *$ \\
\hline Severe & 0.4 & 0.4 & 0.4 & 0.000 \\
\hline Minor & 3.5 & 2.3 & 4.6 & 13.534*** \\
\hline \multicolumn{5}{|l|}{ Injury } \\
\hline Overall & 1.5 & 1.4 & 1.6 & 0.286 \\
\hline Severe & 0.4 & 0.4 & 0.4 & 0.000 \\
\hline Minor & 1.4 & 1.2 & 1.6 & 0.679 \\
\hline
\end{tabular}


Table 5. Comparison of Men's and Women's Reports on Men-to-Women IPV

\begin{tabular}{|c|c|c|c|c|c|c|}
\hline IPV & $\begin{array}{c}\begin{array}{c}\text { Male } \\
(n=1,870)\end{array} \\
\%\end{array}$ & $\frac{\begin{array}{c}\text { Female } \\
(n=1,870)\end{array}}{\%}$ & $\chi^{2}$ & $\begin{array}{c}\text { Kappa } \\
\text { coefficient }\end{array}$ & $\frac{\text { Agreement }^{\mathrm{a}}}{\%}$ & $\frac{\text { Disagreement }^{\mathrm{b}}}{\%}$ \\
\hline \multicolumn{7}{|l|}{ Lifetime } \\
\hline \multicolumn{7}{|l|}{ Physical } \\
\hline Overall & 9.4 & 8.7 & 0.606 & .501 & 91.71 & 8.29 \\
\hline Severe & 3.4 & 3.4 & 0.020 & .362 & 95.76 & 4.24 \\
\hline Minor & 9.2 & 8.5 & 0.533 & .508 & 91.99 & 8.01 \\
\hline \multicolumn{7}{|c|}{ Psychological } \\
\hline Overall & 53.9 & 50.2 & $5.024^{*}$ & .560 & 78.01 & 21.99 \\
\hline Severe & 18.3 & 17.0 & 1.008 & .393 & 82.21 & 17.79 \\
\hline Minor & 53.1 & 49.0 & $5.988^{*}$ & .550 & 77.45 & 22.55 \\
\hline \multicolumn{7}{|l|}{ Sexual } \\
\hline Overall & 7.8 & 8.3 & 0.377 & .452 & 91.79 & 8.21 \\
\hline Severe & 1.8 & 1.4 & 0.746 & .397 & 98.05 & 1.95 \\
\hline Minor & 7.7 & 8.3 & 0.543 & .456 & 91.90 & 8.10 \\
\hline \multicolumn{7}{|l|}{ Injury } \\
\hline Overall & 3.3 & 3.9 & 1.001 & .493 & 96.39 & 3.61 \\
\hline Severe & 1.5 & 1.8 & .644 & .517 & 98.39 & 1.61 \\
\hline Minor & 3.2 & 3.8 & $1.04 \mid$ & .510 & 96.61 & 3.39 \\
\hline \multicolumn{7}{|c|}{ Preceding year } \\
\hline \multicolumn{7}{|c|}{ Physical } \\
\hline Overall & 5.5 & 4.6 & 1.493 & .482 & 95.00 & 5.00 \\
\hline Severe & 1.4 & 1.4 & 0.012 & .344 & 98.18 & 1.82 \\
\hline Minor & 5.3 & 4.5 & 1.353 & .474 & 95.06 & 4.94 \\
\hline \multicolumn{7}{|c|}{ Psychological } \\
\hline Overall & 47.5 & 45.8 & 1.039 & .593 & 79.74 & 20.26 \\
\hline Severe & 34.3 & 33.5 & 0.244 & .502 & 77.60 & 22.40 \\
\hline Minor & 38.7 & 37.2 & 0.888 & .535 & 78.02 & 21.98 \\
\hline \multicolumn{7}{|l|}{ Sexual } \\
\hline Overall & 4.0 & 4.6 & 0.827 & .370 & 94.77 & 5.23 \\
\hline Severe & 0.5 & 0.4 & 0.046 & .113 & 99.16 & 0.84 \\
\hline Minor & 3.9 & 4.6 & 1.163 & .376 & 94.88 & 5.12 \\
\hline \multicolumn{7}{|l|}{ Injury } \\
\hline Overall & 1.7 & 1.6 & 0.052 & .535 & 98.50 & 1.50 \\
\hline Severe & 0.4 & 0.4 & 0.002 & .140 & 99.33 & 0.67 \\
\hline Minor & 1.5 & 1.6 & 0.001 & .554 & 98.61 & 1.39 \\
\hline
\end{tabular}

a. Agreement = \% (Male-yes; Female-yes) + \% (Male—no; Female-no).

b. Disagreement $=($ Male—yes; Female-no $)+($ Male-no; Female-yes $)$.

$*_{p}<.05$.

Similarly, more women than men reported experiencing women-to-men psychological violence in the preceding year (Overall: $49.2 \%$ vs. $44.3 \% ; \chi^{2}=$ $8.66, p<.05$; Severe: $37.6 \%$ vs. $32.4 \% ; \chi^{2}=10.70, p<.05$; Minor: $40.3 \%$ vs. $\left.35.4 \% ; \chi^{2}=9.43, p<.05\right)$. The percentages of interspousal agreement in reports ranged from $75.29 \%$ to $99.56 \%$. The kappa coefficients of all IPV 
Table 6. Comparison of Men's and Women's Reports on Women-to-Men IPV

\begin{tabular}{|c|c|c|c|c|c|c|}
\hline IPV & $\begin{array}{c}\begin{array}{c}\text { Male } \\
(n=1,870)\end{array} \\
\%\end{array}$ & $\frac{\begin{array}{c}\text { Female } \\
(n=1,870)\end{array}}{\%}$ & $\chi^{2}$ & $\begin{array}{c}\text { Kappa } \\
\text { coefficient }\end{array}$ & $\frac{\text { Agreement }^{\mathrm{a}}}{\%}$ & $\frac{\text { Disagreement }^{\mathrm{b}}}{\%}$ \\
\hline \multicolumn{7}{|l|}{ Lifetime } \\
\hline \multicolumn{7}{|l|}{ Physical } \\
\hline Overall & 8.8 & 10.5 & 3.004 & .533 & 91.76 & 8.24 \\
\hline Severe & 3.0 & 3.5 & 0.807 & .453 & 96.51 & 3.49 \\
\hline Minor & 8.6 & 10.1 & 2.543 & .535 & 92.04 & 7.96 \\
\hline \multicolumn{7}{|c|}{ Psychological } \\
\hline Overall & 48.6 & 54.4 & $11.184^{*}$ & .513 & 75.53 & 24.47 \\
\hline Severe & 17.1 & 19.7 & $3.972 *$ & .455 & 83.49 & $16.5 \mid$ \\
\hline Minor & 47.8 & 53.4 & $11.526^{*}$ & .508 & 75.29 & 24.71 \\
\hline \multicolumn{7}{|l|}{ Sexual } \\
\hline Overall & 4.7 & 5.9 & 2.824 & .425 & 94.12 & 5.88 \\
\hline Severe & 1.5 & 1.3 & 0.258 & .423 & 98.37 & 1.63 \\
\hline Minor & 4.6 & 5.9 & 3.096 & .428 & 94.18 & 5.82 \\
\hline \multicolumn{7}{|l|}{ Injury } \\
\hline Overall & 3.3 & 3.3 & 0.004 & .500 & 96.80 & 3.20 \\
\hline Severe & 1.4 & 1.5 & 0.033 & .483 & 98.51 & 1.49 \\
\hline Minor & 3.1 & 3.2 & 0.004 & .519 & 97.02 & 2.98 \\
\hline \multicolumn{7}{|c|}{ Preceding year } \\
\hline \multicolumn{7}{|c|}{ Physical } \\
\hline Overall & 4.6 & 6.0 & 3.576 & .450 & 94.35 & 5.65 \\
\hline Severe & 1.3 & 1.5 & 0.116 & .423 & 98.39 & 1.61 \\
\hline Minor & 4.5 & 5.7 & 2.945 & .453 & 94.63 & 5.37 \\
\hline \multicolumn{7}{|c|}{ Psychological } \\
\hline Overall & 44.3 & 49.2 & $8.662 *$ & .556 & 77.82 & 22.18 \\
\hline Severe & 32.4 & 37.6 & $10.698 *$ & .475 & 75.92 & 24.08 \\
\hline Minor & 35.4 & 40.3 & $9.429 *$ & .503 & 76.50 & 23.50 \\
\hline \multicolumn{7}{|l|}{ Sexual } \\
\hline Overall & 2.4 & 3.2 & 2.207 & .354 & 96.40 & 3.60 \\
\hline Severe & 0.4 & 0.2 & 1.435 & .003 & 99.32 & 0.68 \\
\hline Minor & 2.3 & 3.2 & 2.544 & .359 & 96.46 & 3.54 \\
\hline \multicolumn{7}{|l|}{ Injury } \\
\hline Overall & 1.4 & 1.5 & 0.209 & .483 & 98.51 & 1.49 \\
\hline Severe & 0.4 & 0.3 & 0.311 & .331 & 99.56 & 0.44 \\
\hline Minor & 1.2 & 1.5 & 0.372 & .513 & 98.68 & 1.32 \\
\hline
\end{tabular}

a. Agreement $=\%$ (Male-yes; Female-yes $)+\%$ (Male—no; Female-no).

b. Disagreement $=($ Male-yes; Female-no $)+($ Male-no; Female-yes $)$.

$*_{p}<.05$.

reports, except that of severe sexual violence, ranged from .331 to .556, revealing a moderate agreement. The agreement of reports on severe sexual violence was low $(\kappa=.003)$, which indicated a close-to-zero agreement on the reports between spouses. 


\section{Factors Affecting the Disagreement in Interspousal IPV Reporting}

Table 7 shows the odds ratios of factors believed to be related to the disagreement in the reporting on men-to-women physical IPV. Face, violence approval, and negative attribution were positively associated with the disagreement in the reporting of lifetime IPV. Face and negative attribution were positively related to the disagreement in the reporting of physical IPV in the preceding year. Social desirability, in contrast, was negatively related to the odds of disagreement. However, when all other variables were controlled for, only face (adjusted odds ratio $[\mathrm{OR}]=1.072,95 \%$ confidence interval $[\mathrm{CI}][1.037,1.109], p<.001)$ and negative attribution (adjusted $\mathrm{OR}=$ $1.121,95 \%$ CI $[1.014,1.240], p<.05)$ retained their effect on the disagreement in lifetime IPV. Face was the only factor that had a significant effect on the disagreement in the reporting of IPV in the preceding year (adjusted OR = $1.073,95 \%$ CI $[1.031,1.117], p<.001)$.

Table 8 illustrates the ORs of factors when using the disagreement in women-to-men physical IPV as the dependent variable. Three factors were positively associated with the disagreement in both lifetime and precedingyear IPV reporting: age (35-54), face, and negative attribution; being below 34 was a fourth factor affecting the odds of disagreement in the precedingyear IPV reporting across gender. Social desirability had negative ORs on both the disagreement in lifetime and preceding-year IPV reporting. When controlling for the effect of all the variables, an age range of 35 to 54 (adjusted $\mathrm{OR}=1.574,95 \% \mathrm{CI}[1.080,2.295], p<.05$; when compared with the age group of 55 years or above) and face (adjusted OR $=1.060,95 \%$ CI [1.025, $1.096], p<.001)$ were associated with a disagreement in lifetime IPV reporting, whereas being below 34 (adjusted OR $=3.426,95 \%$ CI [1.944, 6.040], $p<.05$; when compared with the age group of 55 years or above), an age range of 35 to 54 (adjusted OR $=2.192,95 \%$ CI [1.317, 3.650], $p<.01$; when compared with the age group of 55 years or above), and face (adjusted OR = $1.066,95 \%$ CI $[1.024,1.110], p<.01)$ were the remaining significant factors influencing the disagreement in the reports of IPV in the preceding year.

\section{Discussion}

The present study investigated differences in the reporting of various types of IPV perpetration and victimization across gender. Using a large and representative matched-couple sample, the study revealed gender symmetry in selfreports on the prevalence of IPV perpetration and victimization as well as a 


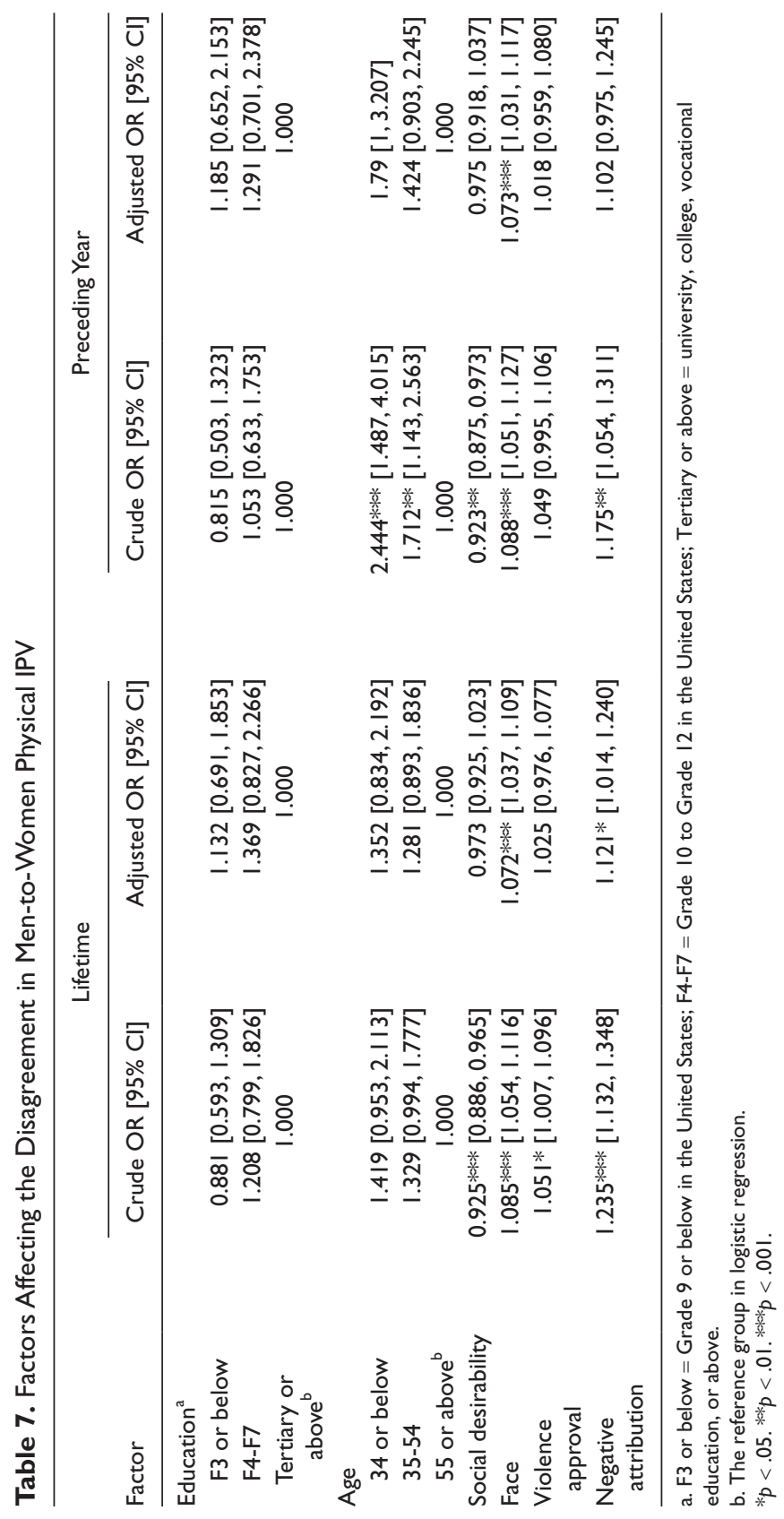




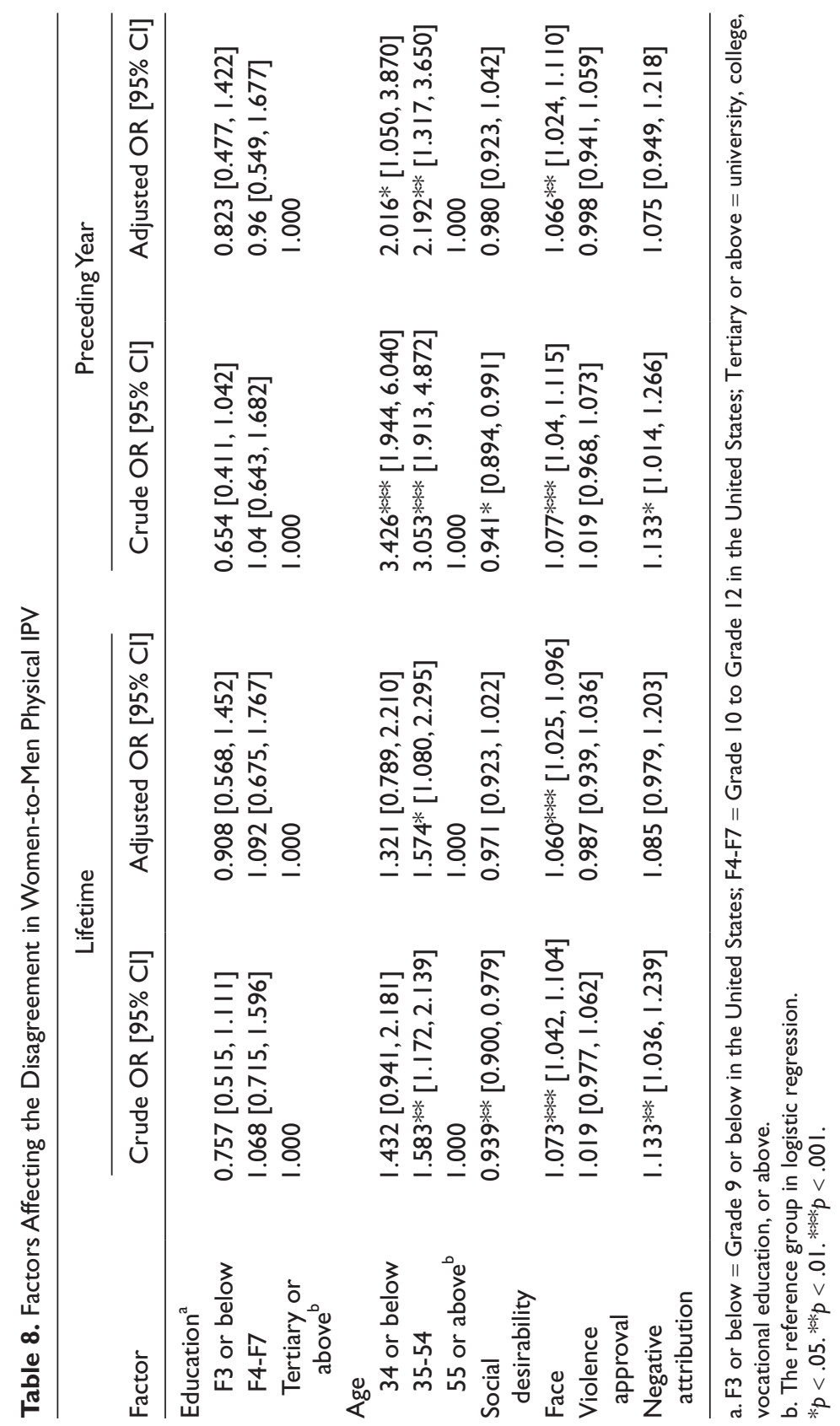


general congruence in self-reported IPV rates between spouses. Several individual characteristics were found to be related to the disagreement in the male and female reports on physical IPV. When the effects of all the variables were controlled for, face and negative attribution were associated with a discrepancy in the reporting of men-to-women IPV, whereas face and age group were associated with a discrepancy in the reporting of women-to-men IPV.

\section{Gender Symmetry in the Prevalence of IPV}

In the present study, the rates of self-reported physical IPV perpetration were comparable across gender, providing a piece of supporting evidence for gender symmetry in IPV prevalence as suggested in previous literature (Cercone, Beach, \& Arias, 2005; Fiebert, 2009; Straus, 2008, 2009; Straus \& Ramirez, 2007). The prevalence rates of lifetime perpetration of physical IPV and sexual IPV were found to range from $9.4 \%$ to $10.5 \%$ and from $5.9 \%$ to $7.8 \%$, respectively. These rates fall into the range of IPV prevalence rates found in previous studies, which vary from $8.7 \%$ to $71 \%$ across the world (Coker, Smith, McKeown, \& King, 2000; Garcia-Moreno, Jansen, Ellsberg, Heise, \& Watts, 2006; Parish, Wang, Laumann, Pan, \& Luo, 2004; Perales et al., 2009). The prevalence of physical or sexual IPV in the preceding year $(3.2 \%$ to $6.0 \%$ ) also falls within the same range of $1.1 \%$ to $54.0 \%$ found in past studies (Garcia-Moreno et al., 2006; Zorrilla et al., 2009).

In line with the findings from Munoz-Rivas et al.'s study (2007[AQ: 4]), more women than men admitted perpetration of psychological IPV - despite the fact that men did not report a higher rate of this type of victimization in the present study. The prevalence of sexual violence was the only type of IPV found to show gender asymmetry. Men were more likely to report minor sexual violence perpetration, and women were more likely to report minor sexual violence victimization. The higher prevalence of male sexual perpetration and female victimization supports previous findings (Kar \& O'Leary, 2010; Rennison \& Welchans, 2000; Tjadens \& Thoennes, 2000), although the discrepancy in the rates of perpetration by gender was not as high (e.g., 100\% of sexual abuse victims were female in Rennison and Welchans's study).

\section{Gender Symmetry in the Reporting of IPV}

The findings of the present study generally revealed no significant gender difference in the reporting of men-to-women or women-to-men IPV. This can be regarded as emerging evidence for a gender symmetry in IPV reporting (McFarlane, Willson, Malacha, \& Lemmey, 2000; Straus \& Ramirez, 2007). 
Significant interspousal disagreement was only found in the reports of psychological IPV: men were more likely to report men-to-women psychological aggression whereas women were more likely to disclose women-to-men psychological violence. Despite the potential effect of gender on IPV reporting, the present findings show that whether the reporter is perpetrator or victim may influence the likelihood of disclosure of IPV. That is, perpetrators appeared to be more likely to report psychological IPV than victims did. This possible perpetrator/victim effect of violence reporting may be worth investigating in future studies.

The use of a matched-couple sample allowed the cross-checking of reports between spouses. When the reports of the two spouses were matched, Cohen's kappa analysis revealed a moderate level of interspousal agreement in the reporting of both men-to-women and women-to-men IPV. The close-to-zero kappa coefficients of severe sexual IPV and injury may suggest a low interspousal agreement for this kind of IPV. However, as the computation of Cohen's kappa coefficients takes into account agreement by chance, the low occurrence of this type of violence (the rates of severe men-to-women sexual IPV, women-to-men sexual IPV, and men-to-women injury as reported by either spouse were $0.84 \%, 0.67 \%$, and $0.68 \%$, respectively), and therefore the large difference between the occurrence and nonoccurrence, may greatly reduce the magnitudes of kappa. Overall, the present findings revealed that underreporting of IPV by men and women was not obvious.

\section{Face:A Common Factor Related}

\section{to the Disagreement in Reporting}

Among all the potentially related factors investigated in the present study, the Chinese concept of "face" was the most robust factor that was positively associated with the interspousal disagreement in both men-to-women and women-to-men physical IPV reporting, after controlling for covariates. "Face," which plays a prominent role in Chinese culture (Carr, 1993), has been regarded as a useful construct for understanding social interaction (Ho, 1976) as it often acts both as a guide for social behavior and a product of social processes (Eberhard, 1967; King \& Myers, 1977). The desire to avoid "losing face" has shaped the behaviors of Chinese people (Eberhard, 1967). As IPV behaviors are socially undesirable, they may evoke feelings of shame and embarrassment (Felson \& Paré, 2005; Knapp \& Kirk, 2003). A sense of "losing face" may occur when perpetrators or victims disclose their violent experiences. To avoid shame and embarrassment, some of the respondents 
may choose to refrain from reporting acts of IPV. As a result, discrepancy in interspousal reports on IPV may arise.

A point to note is that $98 \%$ of the couples in our sample were married. Although conclusive evidence on the relationship between "face" and marital (or cohabiting) status is lacking, the present findings should be interpreted with caution. Whether our findings can be generalized to cohabiting or dating couples is not yet certain. Future research may extend the present study to cover cohabiting or dating couples.

\section{Limitations and Suggestions for Future Studies}

The present study has certain limitations that need to be addressed in future studies. The study was conducted with a retrospective cross-sectional design. As the real prevalence of IPV is almost impossible to detect, no strong conclusion can be made about whether the occurrence of IPV was underreported by either spouse when disagreement existed. There is always a possibility that one spouse overreported the experience of IPV, or, to make the case even more complicated, that a spouse in one couple overreported whereas the other spouse underreported. A longitudinal prospective design, which would allow the tracking of IPV within a set time frame, and the inclusion of reports from other sources (e.g., official police reports, children's or other family member's reports) may help solve this problem.

The use of the CTS2 as a measure for IPV may be another confounding factor in the present study. Some researchers have argued that the CTS may have flaws that lead to a finding of gender symmetry in the prevalence of IPV (Giles, 2004; Kimmel, 2002). The most contentious methodological issue with regard to the CTS may be its failure to capture the intent, circumstances, and consequences of violent acts (Giles, 2004; Kimmel, 2002), despite the effort by a recent review showing that the etiology and context may not differ across gender (Straus, 2010). For example, a woman pushing a man in selfdefense and a man intentionally pushing a woman down the stairs would receive the same CTS score. Future studies might employ other measures of violence to test for agreement in interspousal reports and to see if the findings support gender symmetry in reporting IPV.

The present study found low kappa values, which indicate relatively low agreement between spouses, among severe sexual IPV and injury. As discussed above, the low agreement in reporting may be due to the computation of kappa coefficients, which may be greatly affected by the low occurrence rates of severe IPV, and the use of CTS2, which may have methodological limitations in capturing the real violence situations. However, there may be 
other possible explanations. One of them can be the lower tendency for women to view sexual IPV or injury as severe compared with men. In fact, our findings show lower rates of both perpetration and victimization of these IPV among women's self-reports, although the differences were not significant. Future studies may investigate whether there is any difference in the selfperceived severity levels of IPV between spouses.

Last, as resources were limited, the covariates included in the analysis were not exhaustive. Possible confounding factors can be the gender of interviewers and the length of relationship. As the 2004 survey study neither controlled for the gender of interviewers for male or female participants nor assessed the relationship length, the present findings may be confounded. Future research may consider including these factors and see whether they affect the reporting of violence.

\section{Declaration of Conflicting Interests}

The author(s) declared no potential conflicts of interest with respect to the research, authorship, and/or publication of this article.[AQ: 5]

\section{Funding}

The author(s) disclosed receipt of the following financial support for the research, authorship, and/or publication of this article: This study is commissioned by the Social Welfare Department, and the Government of Hong Kong and funded by the Lotteries Fund.[AQ: 6]

\section{References}

Archer, J. (2000). Sex differences in aggression between heterosexual partners: A meta-analytic review. Psychological Bulletin, 126, 651-680. doi:10.1037/00332909.126.5.651

Armstrong, T. G., Wernke, J. Y., Medina, K. L., \& Schafer, J. (2002). Do partners agree about the occurrence of intimate partner violence? A review of the current literature. Trauma, Violence, \& Abuse, 3, 181-193. doi:10.1177/15248380020033002

Ashton, V. (2004). The effect of personal characteristics on reporting child maltreatment. Child Abuse \& Neglect, 28, 985-997. doi:10.1016/j.chiabu.2004.03.012

Caetano, R., Field, C., Ramisetty-Mikler, S., \& Lipsky, S. (2009). Agreement on reporting of physical, psychological, and sexual violence among White, Black, and Hispanic couples in the United States. Journal of Interpersonal Violence, 24, 1318-1337. doi: $10.1177 / 0886260508322181$

Caetano, R., Schafer, J., Field, C., \& Nelson, S. M. (2002). Agreements on reports of intimate partner violence among White, Black and Hispanic couples in the 
United States. Journal of Interpersonal Violence, 17, 1308-1322. doi:10.1177/ 088626002237858

Carr, M. (1993). Chinese "face" in Japanese and English (Part 2). Review of Liberal Arts, 85, 69-101.

Cercone, J. J., Beach, S. R. H., \& Arias, I. (2005). Gender symmetry in dating intimate partner violence: Does similar behavior imply similar constructs? Violence and Victims, 20, 207-218. doi:10.1891/vivi.2005.20.2.207

Chan, K. L. (2004). Correlates of wife assault in Hong Kong Chinese families. Violence and Victims, 19, 189-201. doi:10.1891/vivi.19.2.189.64104

Chan, K. L. (2005). Study on child abuse and spouse battering: Report on findings of household survey. Hong Kong, China: Department of Social Work \& Social Administration, The University of Hong Kong. Retrieved from http://www.swd.gov.hk/vs/ doc_sc/Report\%20on\%20Findings\%20of\%20Household\%20Survey.pdf

Chan, K. L. (2009). Protection of face and avoidance of responsibility: Chinese men's account of violence against women. Journal of Social Work Practice, 23(1), 93-108. doi:10.1080/02650530902723340

Coben, J. H., Forjuoh, S. N., \& Gondolf, E. W. (1999). Injuries and health care use in women with partners in batterer intervention programs. Journal of Family Violence, 14(1), 83-94. doi:10.1023/a:1022822227669

Coker, A. L., Smith, P. H., McKeown, R. E., \& King, M. J. (2000). Frequency and correlates of intimate partner violence by type: Physical, sexual, and psychological battering. American Journal of Public Health, 90, 553-559. Retrieved from http:// ajph.aphapublications.org/cgi/reprint/90/4/553.pdf

Dobash, R. P., \& Dobash, R. E. (2004). Women's violence to men in intimate relationships: Working on a puzzle. British Journal of Criminology, 44, 324-349. doi:10.1093/bjc/azh026

Dutton, D. G. (1994). Patriarchy and wife assault: The ecological fallacy. Violence and Victims, 9, 167-182.

Eberhard, W. (1967). Guilt and sin in traditional China. Berkeley: University of California Press.

Felson, R. B., \& Paré, P.-P. (2005). The reporting of domestic violence and sexual assault by nonstrangers to the Police. Journal of Marriage \& the Family, 67, 597-610. doi:10.1111/j.1741-3737.2005.00156.x

Fiebert, M. (1997). Annotated bibliography: References examining assaults by women onvtheir spouses/partners. Sexuality and Culture, 1, 273-286. Retrieved from http://news.mensactivism.org/files/fiebert.pdf

Fiebert, M. (2009). References examining assaults by women on their spouses or male partners: An annotated bibliography. Retrieved from http://www.csulb .edu/ mfiebert/assault.htm 
Garcia-Moreno, C., Jansen, H. A. F. M., Ellsberg, M. C., Heise, L., \& Watts, C. (2006). Prevalence of intimate partner violence: Findings from the WHO multicountry study on women's health and domestic violence. Lancet, 368, 1260-1269. doi:10.1016/S0140-6736(06)69523-8

Giles, J. R. (2004). Growing through adversity: Becoming women who live without partner abuse. A grounded theory study. Auckland, New Zealand: School of Psychotherapy, Auckland University of Technology.

Heckert, D. A., \& Gondolf, E. W. (2000). Assessing assault self-reports by batterer program participants and their partners. Journal of Family Violence, 15, 181-197. doi:10.1023/A:1007594928605

Ho, D. F. Y. (1976). On the concept of face. American Journal of Sociology, 81, 867-884. Johnson, M. P. (1995). Patriarchal terrorism and common couple violence: Two forms of violence against women. Journal of Marriage \& the Family, 57, 283-294. doi: $10.2307 / 353683$

Kar, H. L., \& O'Leary, K. D. (2010). Gender symmetry or asymmetry in intimate partner victimization? Not an either/or answer. Partner Abuse, 1(2), 152-168. doi:10.1891/1946-6560.1.2.152

Kimmel, M. S. (2002). "Gender symmetry" in domestic violence: A substantive and methodological research review [Special issue: Women's use of violence in intimate relationships, Part I]. Violence Against Women, 8, 1332-1363. doi:10.1177/107780102762478037

King, A. Y. C., \& Myers, J. T. (1977). Shame as an incomplete conception of Chinese culture: A study of face. Hong Kong: The Chinese University of Hong Kong Social Research Centre.

Knapp, H., \& Kirk, S. A. (2003). Using pencil and paper, Internet and touch-tone phones for self-administered surveys: Does methodology matter? Computers in Human Behavior, 19(1), 117-134. doi:10.1016/s0747-5632(02)00008-0

Landis, J. R., \& Koch, G. G. (1977). The measurement of observer agreement for categorical data. Biometrics, 33, 159-174.

Li, C. L. S. D. (1999). Face orientation and self-disclosure of ability and morality: Does gender make a difference? (Doctoral dissertation). The University of Hong Kong, Hong Kong, China.

McFarlane, J., Willson, P., Malacha, A., \& Lemmey, D. (2000). Intimate partner violence: A gender comparison. Journal of Interpersonal Violence, 15, 158-169. doi: $10.1177 / 088626000015002003$

Moffitt, T. E., Caspi, A., Krueger, R. F., Magdol, L., Margolin, G., Silva, P. A., \& Sydney, R. (1997). Do partner agree about abuse in the relationship? A psychometric evaluation of interpartner agreement. Psychological Assessment, 9(1), 47-56. 
Parish, W. L., Wang, T., Laumann, E. O., Pan, S., \& Luo, Y. (2004). Intimate partner violence in China: National prevalence, risk factors and associated health problems. International Family Planning Perspectives, 30, 174-181. Retrieved from http://ww.psth.org/pubs/joumals/3017404.pdf[AQ: 7]

Perales, M. T., Cripe, S. M., Lam, N., Sanchez, S. E., Sanchez, E., \& Williams, M. A. (2009). Prevalence, types, and pattern of intimate partner violence among pregnant women in Lima, Peru. Violence Against Women, 15, 224-250. doi:10.1177/ 1077801208329387

Rennison, C. M., \& Welchans, S. (2000). Intimate partner violence (Special report). Washington, DC: U.S. Bureau of Justice Statistics, National Institute of Justice.

Rosenbaum, A., \& Langhinrichsen-Rohling, J. (2006). Meta-research on violence and victims: The impact of data collection methods on findings and participants. Violence and Victims, 21, 404-409. doi:10.1891/vivi.21.4.404

Straus, M. A. (1997). Physical assaults by women partners: A major social problem. In M. R. Walsh (Ed.), Women, men and gender: Ongoing debates (pp. 210-221). New Haven, CT: Yale University Press.

Straus, M. A. (2004). Cross-cultural reliability and validity of the Revised Conflict Tactics Scales: A study of university student dating couples in 17 nations. CrossCultural Research: The Journal of Comparative Social Science, 38, 407-432. doi:10.1177/1069397104269543

Straus, M. A. (2005). Women's violence toward men is a serious social problem. In D. R. Loseke, R. Gelles, \& M. M. Cavanaugh (Eds.), Current controversies on family violence (2nd ed., pp. 55-77). Thousand Oaks, CA: SAGE.

Straus, M. A. (2006). Future research on gender symmetry in physical assaults on partners. Violence Against Women, 12, 1086-1097. doi:10.1177/1077801206293335

Straus, M. A. (2008). Dominance and symmetry in partner violence by male and female university students in 32 nations. Children and Youth Services Review, 30, 252-275.

Straus, M. A. (2009). Gender symmetry in partner violence: Evidence and implications for prevention and treatment. In J. R. Lutzker \& D. J. Whitaker (Eds.), Prevention of partner violence (pp. 245-271). Washington, DC: American Psychological Association.

Straus, M. A. (2010). Thirty years of denying the evidence on gender symmetry in partner violence: Implications for prevention and treatment. Partner Abuse, 1, 332-362. doi:10.1891/1946-6560.1.3.332

Straus, M. A., Gelles, R., \& Steinmetz, S. K. (2006). Behind closed doors: Violence in the American family. New York: Doubleday/Anchor Books.

Straus, M. A., Hamby, S. L., Boney-McCoy, S., \& Sugarman, D. (1996). The reivsed Conflict Tactics Scales (CTS2). Journal of Family Issues, 17, 283-316. doi:10.1177/019251396017003001 
Straus, M. A., Hamby, S. L., Boney-McCoy, S., Sugarman, D., DeVoe, E., Dietz, T., ... Yodanis, C. (1999). The personal and relationships profile. Durham: Family Research Laboratory, University of New Hampshire.

Straus, M. A., \& Ramirez, I. L. (2007). Gender symmetry in prevalence, severity, and chronicity of physical aggression against dating partners by university students in Mexico and USA. Aggressive Behavior, 33, 281-290. doi:10.1002/ab.20199

Szinovacz, M. E. (1983). Using couple data as a methodological tool: The case of marital violence. Journal of Marriage \& the Family, 45, 633-644. doi:10.2307/351668

Szinovacz, M. E., \& Egley, L. C. (1995). Comparing one-partner and couple data on sensitive marital behaviors: The case of marital violence. Journal of Marriage \& the Family, 57, 995-1010. doi:10.2307/353418

Tjadens, P., \& Thoennes, N. (1998). Prevalence, incidence, and consequences of violence against women: Findings from the National Violence against Women Survey. Washington, DC: U.S. Department of Justice, National Institute of Justice, U.S. Department of Health and Human Services, and Centers for Disease Control and Prevention.

Tjadens, P., \& Thoennes, N. (2000). Prevalence, incidence, and consequences of violence against women: Findings from the National Violence against Women Survey. Washington, DC: U.S. Department of Justice, National Institute of Justice, U.S. Department of Health and Human Services, and Centers for Disease Control and Prevention.

Wang, H. (2002). Help seeking tendency in situation of threat to self-esteem and facelosing. Hong Kong, China: University of Hong Kong Press.

Weston, R., Temple, J. R., \& Marshall, L. L. (2005). Gender symmetry and asymmetry in violent relationships: Patterns of mutuality among racially diverse women. Sex Roles, 53, 553-571. doi:10.1007/s11199-005-7142-8

Zorrilla, B., Pires, M., Lasheras, L., Morant, C., Seoane, L., Sanchez, L. M., . . . Durban, M. (2009). Intimate partner violence: Last year prevalence and association with socio-economic factors among women in Madrid, Spain. European Journal of Public Health, 20, 169-175. doi:10.1093/eurpub/ckp143

\section{Bio}

Ko Ling Chan is with the Department of Social Work and Social Administration, The University of Hong Kong, Hong Kong, China. 